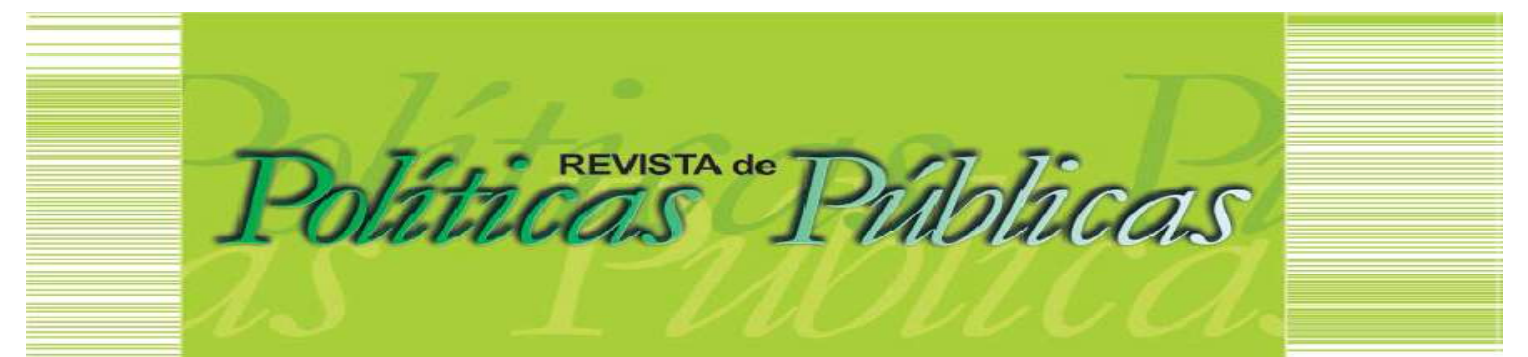

\title{
DESENVOLVIMENTO SUSTENTAVEL E OS CONFLITOS SOCIOAMBIENTAIS PROVOCADOS PELA MINERAÇÃO SOB A INSÍGNIA DO CAPITALISMO DEPENDENTE
}

\author{
Silvana Crisostomo da Silva1
}

\section{Resumo}

Este artigo tem por objetivo analisar os conflitos socioambientais provocados pela mineração relacionando-os ao Desenvolvimento Sustentável. Metodologicamente, baseia-se em análise bibliográfica, documental e cartográfica. 0 desenvolvimento sustentável, propagado como estratégia de mediação de conflitos socioambientais, reforça uma abstrata solução para uma questão estrutural, que é alicerçada na organização do modo de produção capitalista e possui determinantes sociohistóricos, com destaque para os países de capitalismo dependente. Nesse processo, o golpe de Estado intensifica a desregulamentação da mineração brasileira, o que por sua vez, reforça a insustentabilidade socioambiental. Assim, o artigo conclui que o desenvolvimento sustentável escamoteia questões estruturais e que os conflitos socioambientais se dão pela expropriação dos recursos naturais, velados pela relação de classe.

Palavras-chave: Desenvolvimento Sustentável. Conflitos socioambientais. Expropriação. Capitalismo dependente. Mineração

\section{SUSTAINABLE DEVELOPMENT AND THE SOCIO-ENVIRONMENTAL CONFLICTS CAUSED BY MINING UNDER THE BANNER OF DEPENDENT CAPITALISM}

\begin{abstract}
This article aims to analyze the socio-environmental conflicts caused by mining related to Sustainable Development. Methodologically, it is based on bibliographic, documental and cartographic analysis. Sustainable development, propagated as a strategy to mediate socio-environmental conflicts, reinforces an abstract solution to a structural issue, which is based on the organization of the capitalist mode of production and has socio-historical determinants, especially for countries with dependent capitalism. In this process, the coup intensifies the deregulation of Brazilian mining, which in turn reinforces socioenvironmental unsustainability. It is concluded that sustainable development ignores structural issues and that socioenvironmental conflicts are caused by the expropriation of natural resources, veiled by class relations.
\end{abstract}

Keywords: Sustainable Development. Social and environmental conflicts. Expropriation. Dependent capitalism. Mining.

Artigo recebido em: 20/12/2019 Aprovado em: 23/04/2020 DOI: http://dx.doi.org/10.18764/2178-2865.v24n1p108-125.

\footnotetext{
1 Assistente Social. Mestra em Serviço Social pela Universidade Federal de Pernambuco (UFPE). Doutoranda pelo Programa de Pós-Graduação em Serviço Social (PPGSS) da UFPE e Membro do Núcleo de Estudos e Pesquisas sobre Questão Ambiental e Serviço Social (NEPASS/UFPE), coordenado pela Professora Dra. Maria das Graças e Silva. Endereço: Av. Prof. Moraes Rego, 1235 - Cidade Universitária, Recife - PE. CEP 50670-901 E-mail: silvanasilva103@gmail.com.
} 


\section{INTRODUÇÃO}

A atividade mineradora altera substancialmente o meio ambiente, visto que o processo de extração de recursos minerais engloba uma vasta cadeia de degradação ambiental. Além de afetar a vida de milhares de pessoas pela instalação de empresas mineradoras e possíveis barragens de rejeitos, os impactos causados são desde o esgotamento de solo e poluição de nascentes aos problemas de saúde causados pelo contato com os metais pesados, sejam pelo ar ou por outras vias de degradação. Esse processo gera conflitos entre as comunidades afetadas e as empresas mineradoras.

Contraditoriamente, a Organização das Nações Unidas (ONU), responsável pela criação e disseminação do conceito Desenvolvimento Sustentável (DS), reúne no ano de 2015, em sua sede (Nova York), mais de 150 líderes mundiais para fomentar uma agenda em torno de 17 Objetivos de Desenvolvimento Sustentável (ODS). Com o intuito de ser implementado por todos os países do mundo durante 15 anos, ou seja, até 20301.

Nesse sentido, cabe questionar sobre a viabilidade dos ODS concomitante aos conflitos socioambientais provocados pela atividade mineradora. Dessa forma, este artigo tem 0 objetivo de analisar os conflitos socioambientais provocados pela mineração relacionando-os ao Desenvolvimento Sustentável. A metodologia consiste na análise bibliográfica, documental e cartográfica. Os documentos são: Atlas: Mapeando os Objetivos de Desenvolvimento Sustentável na Mineração22, organizado pelas organizações Columbia Center on Sustainable Investment (CCSI), Sustainable Development Solutions Network (SDSN); World Economic Forum e Programa das Nações Unidas para o Desenvolvimento (PNUD); as leis que flexibilizam o Código de Mineração brasileiro. Quanto à dimensão cartográfica do estudo, baseia-se em Environmental Justice Atlas ${ }^{3}$, plataforma criada por pesquisadores/as do Institut de Ciència i Tecnologia Ambientais (ICTA) da Universitat Autònoma de Barcelona (UAB); Mapa de Conflitos Envolvendo Injustiça Ambiental e Saúde no Brasil, vinculado à Fundação Oswaldo Cruz (FIOCRUZ) 4 .

0 desenvolvimento do trabalho está estruturado em três momentos: o primeiro, na apreensão dos conflitos socioambientais a partir da categoria marxiana de expropriação; em seguida, na problematização do desenvolvimento sustentável na atividade mineradora à luz do capitalismo dependente; por fim, a desregulamentação ambiental sobre a mineração com um dos desdobramentos da conjuntura de golpe de Estado no Brasil. 


\section{DESENVOLVIMENTO SUSTENTAVEL E OS CONFLITOS SOCIOAMBIENTAIS PROVOCADOS PELA MINERAÇÃO SOB A INSÍGNIA DO CAPITALISMO DEPENDENTE}

2 CONFLITOS SOCIOAMBIENTAIS E EXPROPRIAÇÃO: desenvolvimento sustentável em xeque

Ao longo da década de 70 do século passado, movimentos e organizações sociais apontavam uma tese: a finitude dos recursos naturais. $O$ que, por sua vez, gerou uma série de debates entre os principais países do centro do poder, orientados pela Organização das Nações Unidas (ONU). Ao longo da discussão, surge, em 1982, um novo conceito que pautará as agendas mundiais, o "Desenvolvimento Sustentável" (DS).

De acordo com o Relatório "Nosso Futuro Comum", o referido conceito pode ser traduzido como "[...] o desenvolvimento que encontra as necessidades atuais sem comprometer a habilidade das futuras gerações de atender suas próprias necessidades" (NAÇÕES UNIDAS, 2018; 1987). Ainda,

Na sua essência, o desenvolvimento sustentável é um processo de mudança no qual a exploração dos recursos, o direcionamento dos investimentos, a orientação do desenvolvimento tecnológico e a mudança institucional estão em harmonia e reforçam o atual e futuro potencial para satisfazer as aspirações e necessidades humanas. (NAÇÕES UNIDAS, 2018; 1987).

O DS trata-se de uma crítica ao modelo-padrão de desenvolvimento, que desprioriza as consequências da exploração da natureza, o que impossibilitará a vida em sociabilidade futura. Assim, propõe-se uma mudança de modelo de desenvolvimento, visando a redução de ações poluentes, com uma série de medidas para tornar a "economia verde", como: "tecnologias limpas" e energias renováveis, a partir do uso de energia eólica, solar, etc.; consumo consciente a partir da redução do consumo, bem como a compra de mercadorias através dos produtores locais; reutilização e reciclagem de resíduos sólidos, dentre outras. A estratégia do DS parte da conciliação entre as dimensões: econômica, social e ambiental.

Dez anos após a criação do conceito do DS, houve a Conferência das Nações Unidas sobre o Meio Ambiente e o Desenvolvimento (CNUMAD), mais conhecida como Rio 92, por ter sido sediada na cidade do Rio de Janeiro, no Brasil. Desse encontro, foi formulado um planejamento para construção de sociedades sustentáveis, com metas para o século 21, chamada de "Agenda 21 Global", com criações de agendas nacionais e locais ${ }^{5}$.

Diante disso, o desenvolvimento sustentável transformou-se em ordem do dia nas elaborações e reordenamento de políticas e planos ambientais. Entretanto, o DS realiza a crítica ao modelo de desenvolvimento atual, que não significa uma crítica ao modo de produção capitalista, tendo em vista que o DS se volta para as possibilidades de mudanças no mercado, nas políticas, nas tecnologias e no comportamento/posturas individuais. Assim, como é possível conceber um desenvolvimento tríade (econômico, social e ambiental) no qual o DS se propõe em uma sociabilidade que possui conflitos em torno dos recursos naturais? 
Acselrad (2004) concebe os conflitos ambientais como

[...] aqueles envolvendo grupos sociais com modos diferenciados de apropriação, uso e significação do território, tendo origem quando pelo menos um dos grupos tem a continuidade das formas sociais do meio que desenvolvem ameaçada por impactos indesejáveis - transmitidos pelo solo, água, ar ou sistemas vivos - decorrentes do exercício das práticas de outros grupos (ACSELRAD, 2004, p.26).

Os conflitos ambientais abarcam a dimensão social por impactar não só o meio, mas também a vida humana, visto que. historicamente, o ser social depende da natureza para viver e se reproduzir. Segundo o Instituto Brasileiro de Análises Sociais e Econômicas (IBASE) (1997), os conflitos socioambientais permeiam relações de poder e "[...] se dão pelo uso da força ou apropriação de espaços e recursos coletivos por agentes econômicos particulares, pondo em jogo interesses que disputam o controle dos recursos naturais e uso do meio ambiente comum [...]". (IBASE, 1997, p. 28).

Os grupos sociais que fazem usos diferenciados dos recursos naturais e a consequente tensão entre interesses em pauta, como citado, apontam uma contradição que não é colocada pelos autores e muito menos pela estratégia do desenvolvimento sustentável, que é a divisão de classes. Tais segmentos afetados são originários da classe trabalhadora e suas diversas frações: trabalhadores/as rurais e urbanos; comunidades quilombola, indígena, camponesa, pesqueira.

Os recursos naturais foram transformados em mercadorias e a disputa perpassa o lugar no qual os segmentos de classe ocupam. Marx (1982) no capítulo 24 d'O Capital, aponta que o surgimento do capitalismo, também chamado, de acumulação primitiva, dá-se pela expropriação: "a expropriação do produtor rural, do camponês, da terra forma a base de todo processo".

No feudalismo, os camponeses possuíam terra cultiváveis, pois recebiam quatro acres ${ }^{6} \mathrm{e}$ uma casa de campo, chamada de cottage. No processo de acumulação primitiva, a terra é expropriada em prol da pastagem (criação de rebanhos de carneiro para a incipiente produção de lã em manufaturas), fazendo com que os povos do campo empobrecidos, sem terras, se tornassem proletários, tendo em vista que lhes restou apenas a força de trabalho para ser vendida.

Nesse processo, o Estado tardiamente criou leis para regular as novas relações produtivas no intuito de amenizar o brutal empobrecimento do "povo do campo da terra", como a proibição da destruição das casas de campo em terrenos com mais de vinte acres, em uma tentativa de controlar o uso de terra, para diminuir a pastagem 7 . Com isso, também houve a limitação de até 2.000 carneiros, visto que alguns proprietários possuíam 24.000 animais $^{8}$ (MARX, 1982).

Posteriormente, o próprio Estado viabilizou essa usurpação, a Revolução Gloriosa inaugurou uma nova era "estas terras foram doadas, vendidas a preços ridículos ou também anexadas a propriedades privadas por usurpação directa". Os capitalistas burgueses transformaram "a terra num 


\title{
DESENVOLVIMENTO SUSTENTAVEL E OS CONFLITOS SOCIOAMBIENTAIS PROVOCADOS PELA MINERAÇÃO SOB A INSÍGNIA DO CAPITALISMO DEPENDENTE
}

puro artigo de comércio, para estenderem o domínio da grande empresa agrícola, para aumentarem o seu abastecimento de proletários fora-da-lei do campo" (MARX, 1982).

Cabe destacar que a expropriação dos camponeses de suas terras ocorreu de forma bastante violenta, "o último grande processo de expropriação do cultivador da terra é finalmente o chamado Clearing of Estates (limpeza das propriedades, de facto, varredura dos homens delas [para fora]), como elucida Marx (1982).

\begin{abstract}
No século XVIII, foi ao mesmo tempo proibida aos gaélicos expulsos do campo a emigração, para os impelir pela força para Glasgow e outras cidades fabris. Como exemplo dos métodos dominantes no século XIX, bastam aqui as 'limpezas' da Duquesa de Sutherland'. Esta pessoa instruída em economia decidiu, logo na sua entrada para o governo, empreender uma cura económica radical e transformar todo o condado - cuja população já anteriormente por processos semelhantes se tinha reduzido em 15000 - em pastagem de carneiros. De 1814 a 1820, estes 15000 habitantes, aproximadamente 3000 famílias, foram sistematicamente expulsos e exterminados. Todas as suas aldeias foram destruídas e reduzidas a cinzas, todos os seus campos foram transformados em pastagens. Soldados britânicos foram encarregados da execução e chegaram a confrontações com os naturais. Uma mulher de idade ardeu nas chamas da choupana que se recusou a abandonar. Assim, esta Madame apropriou-se de 794000 acres de terra, que desde tempos imemoriais pertenciam ao clã. Aos naturais expulsos atribuiu aproximadamente 6000 acres na orla marítima -2 acres por família. Os 6000 acres permaneceram até agora incultos e não deram aos proprietários nenhum rendimento. A duquesa, no seu nobre sentimento, foi ao ponto de arrendar 0 acre, em média, por 2 xelins e 6 dinheiros de renda às gentes do clã que, desde há séculos, haviam vertido o seu sangue pela família. Repartiu toda a terra roubada do clã por 29 grandes quintas de ovelhas, cada uma habitada por uma única família, na maior parte dos casos, criados de quinta ingleses. No ano de 1825, os 15000 gaélicos já estavam substituídos por 131000 carneiros. A parte dos aborígines atirada para a orla marítima procurava viver da captura de peixe. Tornaram-se anfíbios e viviam, como um escritor inglês disse, metade na terra e metade na água e, com isso tudo, só viviam metade de ambas.

Mas, os bons dos gaélicos ainda deviam expiar de um modo mais duro a sua idolatria romântica de montanha pelos «grandes homens» do clã. 0 cheiro do peixe subiu ao nariz dos grandes homens. Farejaram algo de lucrativo por detrás e arrendaram a orla marítima aos grandes negociantes de peixe de Londres. Os gaélicos foram expulsos pela segunda vez.
\end{abstract}

Por fim, aponta as vitórias da burguesia: "eles conquistaram o campo para a agricultura capitalista, anexaram a terra ao capital". Em processo posterior, as Américas e África também sofreram severos processos de expropriações, inclusive, afetando a sua inserção no desenvolvimento capitalista mundial. Marx e Engels (2008, p.9) afirmam, "a descoberta da América e a circunavegação da África abriram um novo campo de ação para a burguesia nascente..".

A expropriação de terras foi a base da acumulação primitiva do capital, porém, não significa que mesmo após o acúmulo de riquezas e desenvolvimento das forças produtivas, esse ato tenha sido extinto. O capitalismo toma formatos e configurações diversas, tendo em vista, as formações sócio-históricas de cada continente, país ou região. No Brasil, a terra representa poder e riqueza, esse processo tem início na regulamentação de venda das terras devolutas através da Lei de Terras (n.601/1850)10 e se perpetua via latifúndio/estruturação fundiária e ausência de reforma agrária, 
inclusive, com criminalização dos movimentos sociais que a reivindicam, como o Movimento dos Trabalhadores Rurais Sem Terra (MST) ${ }^{11}$.

Isso significa dizer que os conflitos socioambientais são expressões da questão social, da desigualdade entre as classes, que a terra ao ser mercantilizada, torna-se objeto de disputa. Dessa forma, a mercantilização da natureza é raiz para entendimento dos conflitos socioambientais. $O$ dito desenvolvimento sustentável é colocado em xeque ao realizar apenas a crítica ao modelo e não ao próprio sistema capitalista, o qual mantém a expropriação como base fundante de sua organização, tanto em sua fase primitiva como atualmente em países de capitalismo dependente.

\section{DESENVOLVIMENTO (IN)SUSTENTÁVEL E A MINERAÇÃO SOB A INSÍGNIA DO CAPITALISMO DEPENDENTE}

A Organização das Nações Unidas (ONU) lançou em setembro de 2015, uma agenda de 17 Objetivos de Desenvolvimento Sustentável (ODS) com a prospecção de ações globais e locais para os próximos quinze anos, são eles: ODS 1: Erradicação da Pobreza; ODS 2: Fome Zero e Agricultura Sustentável; ODS 3: Boa Saúde e Bem-Estar; ODS 4: Educação de Qualidade; ODS 5: Igualdade de Gênero; ODS 6: Água Potável e Saneamento; ODS 7: Energia limpa e acessível; ODS 8: Trabalho Decente e Crescimento Econômico; ODS 9: Indústria, Inovação e Infraestrutura; ODS 10: Redução das Desigualdades; ODS 11: Cidades e Comunidades Sustentáveis; ODS 12: Consumo e Produção Responsáveis; ODS 13: Ação Contra a Mudança Global do Clima; ODS 14: Vida na água; ODS 15: Vida Terrestre; ODS 16: Paz, Justiça e Instituições Eficazes; ODS 17: Parcerias e Meios de Implementação ${ }^{12}$.

Diante disso, vários setores da economia, instituições de ensino, mídia, dentre outros veículos, têm promovido discussões em torno dos ODS. Dessa forma, foi lançado em agosto de 2017, o documento intitulado "Atlas: Mapeando os Objetivos de Desenvolvimento Sustentável na Mineração", voltado para a indústria da mineração, foi construído por um conjunto de organizações: Columbia Center on Sustainable Investment (CCSI), Sustainable Development Solutions Network (SDSN); World Economic Forum e Programa das Nações Unidas para o Desenvolvimento (PNUD).

Dentre todas as medidas, em relação aos recursos naturais, o referido documento propõe: I) Promover 0 acesso à terra, no ODS 1; II) Manter as terras sem poluição, incluindo parceiras com 0 setor do agronegócio, no ODS 2; III) Manter o equilíbrio hídrico em longo prazo por meio de projetos ou políticas ou ações, no ODS 6; IV) Incorporar energia renovável, no ODS 7; V) Planejar o uso do solo cuidadosamente, no ODS 11; VI) Minimizar o uso e desperdício de recursos, no ODS 12; VII) Reduzir 


\section{DESENVOLVIMENTO SUSTENTAVEL E OS CONFLITOS SOCIOAMBIENTAIS PROVOCADOS PELA MINERAÇÃO SOB A INSÍGNIA DO CAPITALISMO DEPENDENTE}

emissões, no ODS 13; VIII) Abordar a mineração no fundo do mar de maneira cautelosa, no ODS 14; IX) Alcançar impactos positivos ou nenhum impacto e preservar os serviços ecossistêmicos, no ODS 15; X) Prevenir e antecipar conflitos, no ODS 16 (CCSI et al., 2017).

Entretanto, as empresas mineradoras na América Latina caminham na contramão das medidas acima. Primeiramente, a terra, os recursos minerais e a água são privatizados, comunidades são expropriadas de suas terras. A prática da atividade mineradora é por si só, poluente e esgotante do solo, em casos de crimes ambientais atingem nascentes de rios e também as águas marítimas. Os ecossistemas são degradados, sem perspectiva de reparação ambiental tendo em vista o manejo de metais pesados.

As empresas mineradoras, como a australiana BHP Billiton e a canadense Belo Sun Mining, ambas instaladas no Brasil, estão envolvidas em questões emblemáticas em torno da questão ambiental. A primeira está envolvida no crime ambiental do rompimento da barragem de rejeitos de Fundão, situada em Mariana - Minas Gerais, em 2015. Movimentos sociais apontaram o panorama dos impactos sociais e ambientais deste acontecimento: "dezenove pessoas morreram, inúmeras famílias ficaram desalojadas, comunidades foram destruídas e assinou-se o atestado de óbito de uma das mais importantes bacias hidrográficas do Brasil, a bacia do rio Doce."13. Esse cenário assolou a região mencionada, como também impactou os Estados da Bahia e do Espirito Santo, visto o deságue das águas poluídas, contaminando o mar. Já a empresa Belo Sun Mining é responsável pela exploração de ouro em região da hidroelétrica Belo Monte, próxima de tribos indígenas, com licenciamento ambiental suspeito de fraudes ${ }^{14}$.

De acordo com o Atlas de Justiça Ambiental: "a extração de matérias-primas nos países da América Latina saltou de 2400 milhões de toneladas em 1970 para cerca de 8300 milhões de toneladas em 2009. Esse boom extrativo é particularmente significativo para os minérios de metal"15. Aos países que ficam na periferia do capitalismo, restam condições mais precarizadas e degradantes, tanto das condições de vida da classe trabalhadora quanto da degradação ambiental, de maneira que as indústrias e atividades de maior impacto sobre o meio ambiente são deslocadas para esses países, caracterizando uma verdadeira "divisão internacional dos custos ambientais".

Mapa 1 - Mining conflicts in Latin America ${ }^{16}$ 


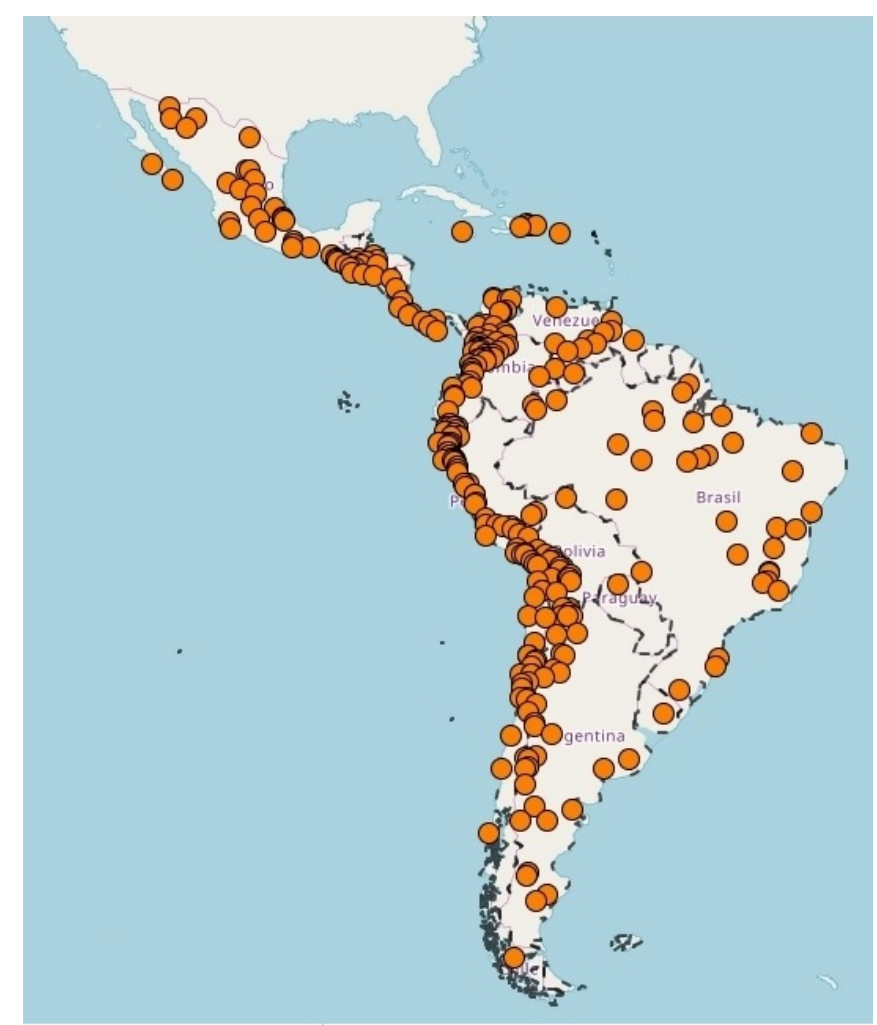

Fonte: Environmental Justice Atlas ${ }^{17}$

A atividade mineradora elucida várias questões, visto que condiciona a economia à reprimarização, fortalecendo a inserção brasileira na divisão internacional do trabalho na qualidade de fornecedor de commodities, agravando a subordinação econômica aos países do capitalismo central. Além disso, promove uma série de consequências tendo em vista ser o fenômeno responsável pelo agravamento da questão ambiental no Brasil, como: apropriação privada dos recursos do subsolo; expropriação territorial de comunidades locais que são afetadas pela exploração de minérios e pela construção de barragens de rejeitos; a degradação ambiental via contaminação de solos e rios e lençóis freáticos; a incidência de diversas doenças nas populações localizadas nos arredores da prática mineradora, principalmente de ordem respiratória e cancerígena, dentre outras.

Mapa 2 - Mapa de conflitos envolvendo injustiça ambiental e saúde no Brasil: mineração, garimpo e siderurgia 18 


\section{DESENVOLVIMENTO SUSTENTAVEL E OS CONFLITOS SOCIOAMBIENTAIS PROVOCADOS PELA MINERAÇÃO SOB A INSÍGNIA DO CAPITALISMO DEPENDENTE}

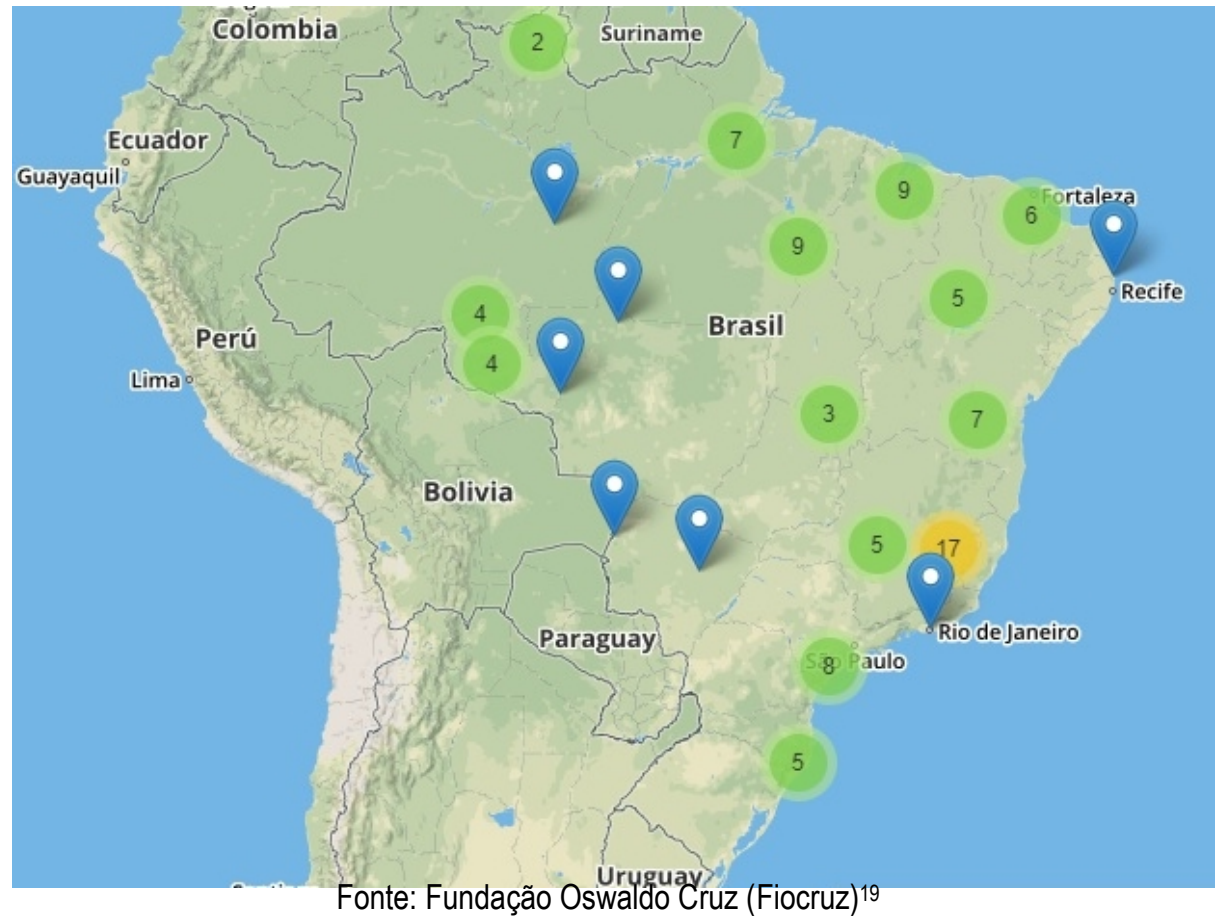

A atividade da mineração perpassa a formação histórico-social do Brasil, desde tempo colonial ao capitalismo vigente e se constitui base da economia, mediante a exportação de minérios. 0 processo de extração desses recursos naturais se dá mediante a apropriação da natureza; assim, a mineração se expressa na questão ambiental. Esta se refere "ao conjunto de manifestações da destrutividade da natureza - cujas raízes encontram-se no desenvolvimento das relações de propriedade - e seus desdobramentos sociopolíticos" (SILVA, 2010, p.82).

Coelho $(2015$, p.199) aponta a destrutividade da natureza através da mineração, elencada em um conjunto de impactos,

1 - Poluição aérea causada pela circulação de pó decorrente do transporte do mineral; 2 Construção e manutenção de represas de rejeitos; 3 - Contaminação, destruição e assoreamento de rios e reservatórios de água; 4 - Poluição sonora causada por explosões e movimentação de carga; 5 - Destruição de sítios arqueológicos; 6 - Remoção de biomas no local da cava; 7 - Utilização de água para transporte em minerodutos, drenagem e separação do minério.

O processo de degradação da natureza se inscreve no circuito de produção das mercadorias (produção, distribuição, troca e consumo). Na mineração, os impactos ambientais se dão pela: privatização da terra das áreas onde possuem minérios; construção de infraestrutura para funcionamento das empresas mineradoras; extração, desde a retirada do minério do (sub)solo até sua separação de outros materiais; uso abundante de água no processo de extração; transporte desses recursos naturais; e, destinação dos rejeitos ${ }^{20}$.

A exploração mineral também resulta em, 
1 - Dumping 16 social e ambiental; 2 - Superexploração do trabalho na cadeia produtiva do minério de ferro e do aço; 3 - Aumento no tráfego local, principalmente quando parte do transporte da produção mineral é feita pelo modal rodoviário; 4 - Alto risco de "acidentes" de trabalho; 5 - Expulsão de populações residentes próximo às minas; 6 - Destruição de formas de produção tradicionais; 7 - Deslocamento de grandes contingentes populacionais para cidades próximas às jazidas; 8 - Inviabilização de formas tradicionais de viver, estar e produzir. (COELHO, 2015, p.117)

O referido autor utiliza o termo dumping social e ambiental, que nada mais é: flexibilizar as leis trabalhistas e ambientais para rebaixamento dos custos e maior obtenção de lucro na exploração humana e da natureza. Esse processo se constitui na superexploração e precarização do trabalho, visto a fragilidade de sua regulamentação, que intensifica a condição de países de capitalismo dependente, ainda mais em momentos de crise do capital, conforme Carcanholo (2013, p.201) "quando os elementos conjunturais se agravam - em um cenário de crise mundial aguda, como se vive neste momento, por exemplo - a condição estrutural dependente é agravada.".

Historicamente, a inserção da América no mercado internacional possibilitou a base de desenvolvimento do capitalismo europeu, conforme destaca Eduardo Galeano na obra clássica "As veias Abertas da América Latina",

É a América Latina, a região das veias abertas. Do descobrimento aos nossos dias, tudo sempre se transformou em capital europeu ou, mais tarde, norte americano, e como tal se acumulou e se acumula nos distantes centros do poder. Tudo: a terra, seus frutos e suas profundezas ricas em minerais e os recursos humanos. 0 modo de produção e a estrutura de classes de cada lugar foram sucessivamente determinados, do exterior, por sua incorporação à engrenagem universal do capitalismo. Para cada um se atribuiu uma função, sempre em benefício do desenvolvimento da metrópole estrangeira do momento, e se tornou infinita a cadeia de sucessivas dependências, que têm muito mais do que dois elos e que, por certo, também compreende, dentro da América Latina, a opressão de países pequenos pelos maiores seus vizinhos [...]. (GALEANO, 2014, p. 18)

Ainda,

Potosí, Zacatecas e Ouro Preto caíram de ponta-cabeça da grimpa de esplendores dos metais preciosos no fundo do buraco dos socavões vazios, e a ruína foi o destino do pampa chileno do salitre e da floresta amazônica da borracha; o nordeste açucareiro do Brasil, as matas argentinas de quebrachos ou certos povoados petrolíferos do lago de Maracaibo têm dolorosas razões para acreditar na moralidade das fortunas que a natureza dá e o imperialismo toma. A chuva que irriga os centros do poder imperialista afoga os vastos subúrbios do sistema. Desse modo, e simetricamente, o bem-estar de nossas classes dominantes - dominantes para dentro, dominadas de fora - é a maldição de nossas multidões, condenadas a uma de bestas de carga. [grifo do autor] (ibid, p.19)

O trecho destacado por Galeano ilustra a condição do capitalismo dependente, sendo destinado ao país a subordinação via exploração da natureza e à classe trabalhadora a superexploração do trabalho. Durante o período do escravismo colonial21, o modelo econômico baseava-se na forma plantagem, predominantemente, a partir da monocultura, em grandes extensões de terras, os latifúndios, com força de trabalho utilizada de forma escrava e produção destinada para exportação (VALADÃO; BARCELLOS, 2012). A despeito do fim do regime de escravismo no Brasil e a 


\section{DESENVOLVIMENTO SUSTENTAVEL E OS CONFLITOS SOCIOAMBIENTAIS PROVOCADOS PELA MINERAÇÃO SOB A INSÍGNIA DO CAPITALISMO DEPENDENTE}

adoção do trabalho assalariado22, a estruturação fundiária mantém-se quase inalterada, com a extinção do uso de força de trabalho escrava.

A manutenção desse modelo perpetua a primarização da economia, ou seja, a exportação de matérias primas. Mesmo com o desenvolvimento da indústria nacional, o país manteve-se como exportador, condicionante da dependência ao mercado mundial, visto que "a expansão do mercado mundial é a base sobre a qual opera a divisão internacional do trabalho entre nações industriais e as não industriais, mas a contrapartida dessa divisão é a ampliação do mercado mundial'. (MARINI, 2011, p.144).

De acordo com Marini (2011), a inserção da América Latina no mercado mundial acompanhou a queda dos preços de alimentos e matérias-primas quando comparada ao preço das manufaturas, a depreciação dos bens primários propiciou o início de uma troca desigua/23.

[...] transações entre nações que trocam distintas classes de mercadorias, como manufaturas e matérias-primas-, o mero fato de que umas produzam bens que as outras não produzem, ou não o fazem com a mesma facilidade, permite que as primeiras iludam a lei do valor, isto é, vendam seus produtos a preços superiores a seu valor, configurando assim uma troca desigual. Isso implica que as nações desfavorecidas devem ceder gratuitamente parte do valor que produzem, e que essa cessão ou transferência seja acentuada em favor daquele país que thes venda mercadorias a um preço de produção mais baixo, em virtude de sua maior produtividade (MARINI, 2011, p.145).

Como forma de compensar as perdas, a América Latina carrega a exploração ainda maior da força de trabalho, a extração de mais valia absoluta associada à precária reposição da força de trabalho, o que Marini (2011) aponta como uma superexploração do trabalho. A partir disso, nos interessa destacar que não só existe uma superexploração do trabalho, como também uma superexploração dos recursos naturais, tendo em vista que essas matérias primas exportadas se configuram como natureza.

Atualmente, o capitalismo dependente se reatualiza em articulação à sua financeirização, visto que se tem a exportação de commodities sob o regimento do capital financeiro, que significa dizer: a venda de recursos naturais (sua transformação em mercadoria) passa a ser negociada no mercado financeiro mundial em forma de ações, títulos. Após o processo de privatização da Companhia Vale do Rio Doce (CVRD)24 para o capital estrangeiro, que se tornou Vale S.A. - empresa multinacional, há o intenso processo de financeirização da natureza, como aponta Coelho (2015, p.43), "durante a administração Roger Agnelli (2001 - 2011), as ações da empresa valorizaram 834\%, o que demonstra que o foco da empresa, desde então, tem sido promover boas relações com o mercado financeiro.".

lamamoto (2011, p.101) elucida que "o capital financeiro envolve a fusão do capital bancário e industrial em condições de monopólio capitalista, redundando na concentração da produção e na fusão de bancos com a indústria". Tal grupo é denominado como uma oligarquia financeira, que 
"tende a crescer com os lucros excepcionais, os empréstimos estatais, a especulação com terras, dentre outros mecanismos" (IAMAMOTO, 2011, p.101). Netto (2012, p. 419) alerta acerca do tal espraiamento dessa forma "regenerada" do capital, a oligarquia financeira, a qual "[...] controla 0 conjunto das riquezas sociais e exerce uma determinante ação planetária que inclusive ladeia as instâncias democrático-formais consagradas no Estado de direito".

No século XXI, o capital a juros tornou-se a principal forma de rendimento no modelo de acumulação flexível. Corroborando com Antunes (2010, p.191), essa perversa conjuntura - barbárie se manifesta na "destruição e/ou precarização [...] na relação metabólica entre homem e natureza, conduzida pela lógica voltada prioritariamente para a produção de mercadorias que destrói 0 meio ambiente". Portanto, esse processo se constitui em um nó que emaranha a destruição da natureza, a condição de capitalismo dependente e evidencia o desenvolvimento insustentável da sociabilidade atual.

\section{PROCESSO DE GOLPE E AS INFLEXÕES NA REGULAMENTAÇÃO DA MINERAÇÃO BRASILEIRA}

Em 2016 foi instaurado juridicamente o impeachment da presidenta Dilma Rousseff, entretanto, diversos segmentos da sociedade corroboram para a tese de que esse processo foi um golpe na democracia brasileira25. Lowy (2016) denominou esse processo de "golpe de Estado legal" e afirma que tal prática "parece ser a nova estratégia das oligarquias latino-americanas". A conjuntura atual nos remonta a questionar o modelo de democracia e a própria estrutura do Estado, inclusive, as particularidades de um capitalismo periférico, no caso do Brasil.

A própria forma organizativa moderna desse Estado, pela "democracia", remonta a um passado conservador ainda não superado. Lowy (2016) afirma que "[...] a tragédia de 1964 e a farsa de 2016 têm em comum é o ódio à democracia. Os dois episódios revelam o profundo desprezo que as classes dominantes brasileiras têm pela democracia e pela vontade popular". Fernandes (2017) historiciza marcas ainda mais profundas da democracia brasileira,

\footnotetext{
Nunca haverá democracia no Brasil nem será possível a existência de uma república democrática enquanto persistir a desigualdade racial e a discriminação dos negros. Trata-se de uma liberação às avessas: o antigo escravo carrega consigo a solução do dilema número um do Brasil, pois de sua autoemancipação coletiva depende a autoridade legítima e o próprio destino das camadas senhoriais, dos seus descendentes e sucessores desenraizados da sociedade escravocrata. Voltamos a dialética do senhor e do escravo, apontada por Hegel. Ou ambos serão livres, ou a liberdade de um forjará a sujeição do outro, bloqueando o advento da democracia como estilo de vida (FERNANDES, 2017, p. 149).
} 


\title{
DESENVOLVIMENTO SUSTENTAVEL E OS CONFLITOS SOCIOAMBIENTAIS PROVOCADOS PELA MINERAÇÃO SOB A INSÍGNIA DO CAPITALISMO DEPENDENTE
}

Em pleno século XXI, essa estrutura desigual (racista e classista) de sociedade e Estado tornou-se evidente há dois anos com o golpe, que determina os mandos e desmandos dessa elite com características senhoriais, que atende aos interesses de uma burguesia internacional. Esse processo também pontua a ausência de um projeto de nação, condicionando a um Estado dependente.

Marx (2012), ao tratar do Estado na revisão do Programa de Gotha, realiza uma crítica aos termos "sociedade atual" e "Estado atual" utilizados no referido documento. 0 autor reivindica a problematização de qual sociedade e Estado seriam, e alerta para a utilização da categoria de "sociedade capitalista" e da ficção de um "Estado atual" porque mesmo com particularidades da formação histórica, os Estados ocidentais assentam a "moderna sociedade burguesa".

\begin{abstract}
A 'sociedade atual' é a sociedade capitalista, que, em todos os países civilizados, existe mais ou menos livre dos elementos medievais, mais ou menos modificada pelo desenvolvimento histórico particular de cada país, mais ou menos desenvolvida. O 'Estado atual', ao contrário, muda juntamente com os limites territoriais do país. No Império prussiano-alemão, o Estado é diferente daquele da Suíça; na Inglaterra, ele é diferente daquele dos Estados Unidos. "O Estado atual" é uma ficção. No entanto, os diferentes Estados dos diferentes países civilizados, apesar de suas variadas configurações, têm em comum o fato de estarem assentados sobre 0 solo da moderna sociedade burguesa, mais ou menos desenvolvida em termos capitalistas. É o que confere a eles certas características comuns essenciais. (MARX, 2012, p. 42)
\end{abstract}

Nesse fragmento supracitado é importante destacar o reconhecimento de Marx pela essência da sociedade e Estado burgueses, ao mesmo tempo que reconhece as "variadas configurações" postos aos diferentes países. Diante disso, corroboramos com a tese que de o Estado brasileiro incorpora-se ao modo de produção capitalista, mas perpetua em seu desenvolvimento traços coloniais, marcando a fragilidade no desenvolvimento da democracia.

A particularidade brasileira, marcada pela dependência, perpetua a estruturação fundiária, ao manter a base da economia brasileira pautada na monocultura, no latifúndio e na produção de commodities voltada para a exportação. Neste contexto, acentua o grau de exploração do trabalho e intensifica a apropriação privada dos recursos naturais. No que concerne aos recursos naturais, em especial, aos recursos minerais, existe uma intensificação da destruição, mediada por uma (des)regulamentação ambiental.

A luta travada pelas comunidades afetadas pela mineração se acirra a partir de propostas de mudanças no atual Código de Mineração, com base nos Projetos de Lei (PL) 37/2011, PL 5807/2013, PL 3726/2015, PL 5263/2016. Para formulação de um novo Código de Mineração, considerando os diversos projetos mencionados, criou-se a Comissão Especial do Novo Código de Mineração. Com o intuito de investigar os interesses que permeiam tais mudanças, o Comitê Nacional em Defesa dos Territórios Frente à Mineração fez uma importante descoberta sobre a referida comissão: "dos 27 deputados titulares da comissão, apenas 7 não receberam doações dessas 
empresas, o restante recebeu, sendo que a metade desses receberam $20 \%$ ou mais." (OLIVEIRA, 2014, p.12).

A relação entre os proponentes de mudanças no marco regulatório da mineração e 0 financiamento privado de campanhas pelas empresas mineradoras também foi evidenciada pelo Grupo Política, Economia, Mineração, Ambiente e Sociedade (PoEMAS), vinculado à Universidade Federal de Juiz de Fora (UFJF). No relatório intitulado "Antes fosse mais leve a carga: avaliação dos aspectos econômicos, políticos e sociais do desastre da Samarco/Vale/BHP em Mariana (MG)" (PoEMAS, 2015) se destaca a doação das referidas empresas para candidatos à presidência do país, bem como senadores e deputados federais. $O$ financiamento privado de campanha possibilita a criação do que se pode chamar de "candidato ouro": a empresa de mineração financia a campanha do candidato, que quando eleito, beneficia a empresa financiadora através de desregulamentações de proteção ambiental, constituindo-se em um processo de "moeda de troca".

Atualmente, pode-se destacar a lei $n^{0}$ 13.540/2017: cobrança de royalties através da Compensação Financeira pela Exploração de Recursos Minerais (CFEM) e a lei $n^{0}$ 13.575/2017: mudança institucional-administrativa. A lei $n^{0}$ 13.540/2017 modificou as regras da cobrança da CFEM²6, que passa a ser calculada com base na receita bruta e não mais na receita líquida, porém a referida lei ainda mantém o valor abaixo de outros recursos naturais. Milanez $(2012$, p.70) aponta que os royalties da exploração de petróleo e gás constituem $10 \%$ do valor de óleo e gás brutos; dos recursos hídricos para geração de eletricidade são $7,5 \%$ do valor de energia produzida; já os recursos minerais variam entre $0,2 \%$ a $3,0 \%$. A CFEM mostra-se insuficiente para reparar os danos aos municípios e comunidades afetadas e seu baixo valor funciona como incentivo à prática mineradora, principalmente às empresas internacionais. Todo esse processo deixou de ser fomentado pelo Departamento Nacional de Produção Mineral e passou a ser pela Agência Nacional de Mineração, uma autarquia que integra a administração pública indireta, criada pela lei 13.575/2017.

As propostas aprovadas pelos poderes: legislativo (câmara dos deputados e senado federal) e executivo (presidência do país) fragilizam a proteção ambiental e reforçam a expropriação e dilapidação da natureza, elevando a extração mineral, no país, a uma das principais mercadorias inseridas no ciclo do capital na economia dependente, que se reatualiza diante da financeirização, da crise estrutural do modo de produção capitalista e da insustentabilidade ambiental.

\section{CONSIDERAÇÕES FINAIS}




\section{DESENVOLVIMENTO SUSTENTAVEL E OS CONFLITOS SOCIOAMBIENTAIS PROVOCADOS PELA MINERAÇÃO SOB A INSÍGNIA DO CAPITALISMO DEPENDENTE}

Sob a ordem do capital, a natureza torna-se uma mercadoria. A dilapidação ambiental se acirra em países de capitalismo dependente visto que esse processo não se dá apenas pela superexploração da força de trabalho, mas da apropriação privada dos recursos naturais. Diante disso, ganha destaque a atividade mineradora, pois a extração mineral causa inúmeros impactos socioambientais, além de esta ser a principal mercadoria exportada, a exemplo do minério de ferro. Esse processo culmina em milhares de conflitos socioambientais na América Latina, que são marcados pela expropriação, determinando a condição estrutural dessa problemática ao modo de produção capitalista, o que enaltece a dimensão de classe desses conflitos.

Em tempos de crise estrutural do capitalismo, há uma intensificação dos processos exploratórios já existentes. Para isso, existe uma grande ofensiva em prol da fragilização das leis ambientais, com destaque para o "Novo Código de Mineração", que aumenta a desresponsabilização do Estado e abre precedentes para novas áreas de exploração mineral e consequentes crimes ambientais. Inclusive, porque os países centrais possuem consolidadas legislações ambientais, despejando o que não serve mais na periferia do capitalismo, como as práticas mais predatórias, a exemplo da mineração.

Esse processo ocorre a baixos custos concernentes ao pagamento de impostos, apesar da alta rentabilidade para a oligarquia financeira. Concomitantemente, o capitalismo rentista disputa 0 fundo público e atuam na desregulação ambiental visto que a exploração mineral tem sido feita por corporações multinacionais, que necessitam da autorização pública para explorarem os recursos. Os interesses que constituem a fragilização da proteção ambiental brasileira, aliada à falaciosa estratégia do Desenvolvimento Sustentável, escamoteiam as novas roupagens da dependência e a disputa dos recursos naturais, sob o alicerce do Estado brasileiro.

\section{REFERÊNCIAS}

ACSELRAD, Henri. As práticas espaciais e o campo dos conflitos ambientais. In (org.)

Conflitos ambientais no Brasil. Rio de Janeiro: Relume-Dumará, 2004. p.13-36.

ANTUNES, Ricardo. Adeus ao Trabalho? Ensaio sobre as metamorfoses e a centralidade no mundo do trabalho. 14 ed. São Paulo: Cortez, 2010.

CARCANHOLO, Marcelo Dias. 0 atual resgate crítico da Teoria da Marxista da Dependência. Rio de Janeiro, Trab. Educ. Saúde, v. 11 n. 1, 2013.

CCSI et al. Atlas: Mapeando os Objetivos do Desenvolvimento Sustentável. Genebra: Fórum Econômico Mundial, 2017. 
COELHO, Tádzio Peters. Projeto Grande Carajás: trinta anos de desenvolvimento frustrado. In ZONTA, Marcio. TROCATE, Charles (orgs.). A questão mineral no Brasil. v.1. Marabá: Editora iGuana, 2015.

FERNANDES, Florestan. Consciência negra e transformação da realidade. In: Significado do

Protesto Negro. São Paulo: Expressão Popular; Fundação Perseu Abramo, 2017.

GALEANO, Eduardo. As veias abertas da América Latina. Tradução de Sergio Faraco. Porto Alegre: L\&PM, 2014.

IAMAMOTO, Marilda. Serviço Social em tempo de capital fetiche: capital financeiro, trabalho e questão social. 5 ed. São Paulo: Cortez, 2011.

IBASE. Conflitos ambientais no Brasil: natureza para todos ou somente para alguns? Rio de Janeiro: IBASE, 1997.

LOWY, Michael. O golpe de Estado de 2016 no Brasil. In Blog da Boitempo. São Paulo: Boitempo, 2016. Disponível em: https://blogdaboitempo.com.br/2016/05/17/michael-lowy-o-golpe-de-estado-de2016-no-brasil/. Acesso em: 2. abr. 2018.

MARINI, Ruy Mauro. Dialética da dependência. In: TRASPADINI, Roberta. STEDILE, João Pedro (orgs.). Ruy Mauro Marini: vida e obra. 2 ed. São Paulo: Expressão Popular, 2011.

MARX, Karl. O Capital. Obras Escolhidas. Lisboa: Editorial Avante, 1982. Disponível em: https://www.marxists.org/portugues/marx/1867/capital/cap24/index.htm. Acesso em: 21 dez. 2018.

Crítica do Programa de Gotha. Seleção, tradução e notas de Rubens Enderle. São Paulo: Boitempo, 2012.

; ENGELS, Friedrich. Manifesto do Partido Comunista. São Paulo:

Expressão Popular, 2008.

MILANEZ, Bruno. O novo marco legal da mineração: contexto, mitos e riscos. In: MALERBA, Julianna. MILANEZ, Bruno. WANDERLEY, Luiz Jardim (orgs.). Novo Marco da Mineração no Brasil: Para quê? Para quem? Rio de Janeiro: FASE, 2012.

NAÇÕES UNIDAS. A ONU e o meio ambiente. 2018. Disponível em:

https://nacoesunidas.org/acao/meio-ambiente/. Acesso em: 10 fev. 2019.

Nosso futuro comum. 1987. Disponível em: http://www.un-documents.net/our-commonfuture.pdf. Acesso em: 10 fev. 2019.

NETTO, José Paulo. Crise do capital e consequências societárias. Serviço Social e Sociedade, São Paulo, n.111, 2012.

OLIVEIRA, Clarissa Reis. Quem é quem nas discussões do Novo Código de Mineração. Brasília: Comitê Nacional em Defesa dos Territórios Frente à Mineração, 2014.

SILVA, Maria das Graças e. Questão Ambiental e Desenvolvimento Sustentável: um desafio éticopolítico ao Serviço Social. São Paulo: Cortez, 2010. 


\title{
DESENVOLVIMENTO SUSTENTAVEL E OS CONFLITOS SOCIOAMBIENTAIS PROVOCADOS PELA MINERAÇÃO SOB A INSÍGNIA DO CAPITALISMO DEPENDENTE
}

\author{
VALADÃO, Vanda de Aguiar. BARCELLOS, Gilsa Helena. Privatização da terra: intersecções das \\ questões agrária e ambiental. Revista Temporalis, Vitória, v. 2, n 24, 2012. Disponível em: \\ http://periodicos.ufes.br/temporalis/article/view/3080/3288. Acesso em: 10 fev. 2019.
}

\section{Notas}

1 Disponível em: https://nacoesunidas.org/conheca-os-novos-17-objetivos-de-desenvolvimento-sustentavel-da-onu/. Acesso em: 16 fev.2019.

2 Disponível em:

http://www.undp.org/content/dam/undp/library/Sustainable\%20Development/Extractives/Mining\%20Atlas\%20Vers\%C3\%A30 \%20Final_Lan\%C3\%A7amento_Portuguese.pdf. Acesso em: 14 set. 2018.

${ }^{3}$ A plataforma está disponível no sítio eletrônico: https://ejatlas.org/.

${ }^{4}$ Disponível em: http://mapadeconflitos.ensp.fiocruz.br.

5 Disponível em: http://www.mma.gov.br. Acesso em 16 fev. 2019.

${ }^{6}$ Acre é uma antiga medida de terras, que equivale a aproximadamente 4.000 metros quadrados.

${ }^{7}$ Lei criada pelo Rei da Inglaterra, Henrique VII, em 1489.

8 Lei de 1533.

9 “(1765-1839): marquesa de Strafford, a partir de 1833 duquesa. Grande proprietária agrária da Escócia [...]". Disponível em: https://www.marxists.org/portugues/dicionario/verbetes/s/sutherland_elizabeth.htm. Acesso em: 17 fev. 2019.

10 Disponível em: http://www.planalto.gov.br/ccivil_03/LEIS/L0601-1850.htm. Acesso em 16 fev. 2019.

11 Ver matéria especial "Violência no campo e o padrão de criminalização dos movimentos sociais". Disponível em: http://www.mst.org.br/2018/09/04/violencia-no-campo-e-o-padrao-de-criminalizacao-dos-movimentos-sociais.html. Acesso em: 16 fev. 2019.

12 Disponível em: https://nacoesunidas.org/pos2015/agenda2030/. Acesso em: 14 dez. 2018.

13 Disponível em: https://atingidospelavale.wordpress.com.

${ }^{14}$ No início de 2019, o rompimento da barragem da Mina do Córrego do Feijão em Brumadinho (MG), da empresa Vale, tornou-se um crime ambiental com dimensões ainda mais avassaladoras do ocorreu em Mariana (MG), com o resultado de 252 pessoas assassinadas, além da morte do rio Paraobepa e rejeitos no rio São Francisco.

15 Disponível em: https://ejatlas.org/featured/mining-latam. Acesso em 17 fev. 2019.

16 Conflitos na mineração na América Latina.

17 Disponível em: https://ejatlas.org/featured/mining-latam. Acesso em: 16 fev. 2019.

${ }^{18}$ A plataforma evidencia 98 conflitos em torno da mineração, garimpo e siderurgia, no Brasil.

19 Disponível em:http://mapadeconflitos.ensp.fiocruz.br/?atv_gerad=mineracao\&post_types=conflito. Acesso em: 16 fev. 2019.

20 De acordo com o inciso XV do art. $3^{\circ}$ da Política Nacional de Resíduos Sólidos (Lei $\left.n^{0} 12.305 / 2012\right)$ define como rejeitos: "resíduos sólidos que, depois de esgotadas todas as possibilidades de tratamento e recuperação por processos tecnológicos disponíveis e economicamente viáveis, não apresentem outra possibilidade que não a disposição final ambientalmente adequada". 
${ }^{21}$ Ver GORENDER, Jacob. O escravismo colonial. 6. Ed. São Paulo: Expressão Popular: Perseu Abramo, 2016.

22 Para apreender determinantes do referido processo, ver OLIVEIRA, Francisco de. A questão regional: a hegemonia inacabada. São Paulo: Estudos Avançados, v.7, n.18, 1993. Disponível em:

http://www.revistas.usp.br/eav/article/view/9622/11191.

${ }^{23} \mathrm{~A}$ regulamentação das relações de troca constituía a própria anarquia da produção, "teoricamente, o intercâmbio de mercadorias expressa a troca de equivalentes, cujo valor se determina pela quantidade de trabalho socialmente necessário que as mercadorias incorporam. Na prática, observam-se diferentes mecanismos que permitem realizar transferências de valor, passando por cima das leis da troca, e que se expressam na forma como se fixam os preços de mercado e os preços de produção das mercadorias" (MARINI, 2011, p.144).

${ }^{24}$ A privatização da CVRD se configura como medida da agenda neoliberal, implementada durante o governo de Fernando Henrique Cardoso, através do Programa Nacional de Desestatização. Ver PASTORINI, Alejandra. GALIZIA, Silvina. A redefinição do padrão de proteção social brasileiro. Rio de Janeiro: Praia Vermelha - Estudos de Política e Teoria Social, n. 14 e 15, 2006.

25 Ver JINKINGS, Ivana; DORIA, Kim; CLETO, Murilo (org.). Por que gritamos golpe? Para entender o impeachment e a crise. llustração de Laerte Coutinho. São Paulo: Boitempo, 2016.

${ }^{26}$ A CFEM foi criada para "compensação pelo consumo de um recurso não renovável, e a compreensão de que os principais impactos da exploração mineral ocorrem no local de extração.". (MILANEZ, 2012). 